\title{
Pygmalion im OP
}

\author{
Erhard Taverna
}

Wenn man dem Hochglanzmagazin «beauty science» glauben darf, werden allein in Deutschland täglich zehn ästhetische Brustveränderungen vorgenommen. Bei Damen versteht sich. Der neue Typ Arzt sei ein Erlöser, steht da, er hantiere seine Fettabsaugkanüle als führte er einen Violinbogen. Das Krankenhaus mutiere zum Ästhetiksalon, wo ein Verbund aus Ärzten, Pharmakonzernen und Kunden am Ideal des makellosen Menschen strickten. «Umgeben von Nofretete-Büsten oder Nachdrucken von Botticellis Venus saugen, schlitzen und nähen selbst deutsche Universitätskliniker für den kosmetischen Endsieg.»

Gemäss Ovid verliebte sich Pygmalion in sein elfenbeinernes Auftragswerk, worauf die Göttin Aphrodite sich seiner erbarmte und die Statue zum Leben erweckte. Dem Abbild der Venus, die wir zurzeit am Eingang zur Ausstellung «Liebeskunst» im Museum Rietberg in Zürich bewundern dürfen, ist unsere Kultur treu geblieben. Ihr Körper ist immer noch das Vorbild für eine attraktive, erotische Weiblichkeit. Sex sells. Warum soll die Medizin an der engen Beziehung von Erfolg und Ästhetik nicht mitverdienen?

Es wird kunstvoll und lustvoll kopuliert in den Kellerräumen der ehemaligen Fabrikantenvilla Wesendonck. Wagner, den hier Liebesleid zum Komponieren anregte, hätte am multikulturellen Kunstniveau Gefallen und vielleicht auch Trost und Inspiration gefunden. Der Prüderie seiner Epoche folgt der vermarktete Exhibitionismus, wo das Verhüllen schon wieder exotisch wirkt. Die Nachfahren jener Zunft, die wortreich und gelehrt den Teufel der Masturbation an die Wand malte, sind heute die Sexualforscher und ihre medizinischen Handwerker. Der römische Phallus als magisches Amulett feiert in der erektilen Dysfunktion seine Wiederauferstehung. Doch besser als seine Vorbilder wirken Viagra und Co. Und, wir nehmen es zumindest an, auch wirksamer als die Aphrodisiaka aller abgebildeten feudal-hinduistischen und moslemischen Fürstenhöfe. Hormonlabors, Evolutionstheoretiker und Sozialpsychologen sind dem Triebleben auf der Spur, basteln am Bindungsmodell und rätseln über die Logik der Liebe. Das Glück liegt in der industriellen Retorte oder in den Bestsellern des positiven Denkens. Was Wilhelm Reich den Rauswurf aus allen kollegialen Gesellschaften und die soziale Ächtung eintrug, würde ihn in unserer Zeit, unternehmerisch nachgebessert, zum börsenkotierten Unternehmer machen. Denn seine 1940 gebaute Orgonkiste ist inzwischen in verfeinerter Form gesellschaftsfähig. Das kantige Kiefernholz hat die Wellnesseuphorie zur Sauna verfeinert, und aus dem Stahlblech des sperrigen Akkumulators wurden die glatt-metallisierten Karosserien unserer Lustmobile. Nun dürfte es keine Neurosen und Krankheiten mehr geben, denn in der frei zirkulierenden Orgonenergie vermutete er den Schlüssel zur Gesundheit. Lustreaktionen sind messbar und steuerbar, ihre Energien beflügeln den Konsum und sind eine der wenigen noch verbliebenen Wachstumsbranchen. Die Vermarktung des Körpers, bei Spitzensportlern schon lange akzeptiert, wird allmählich in fortschrittlicheren Ländern auch den Prostituierten zugestanden. Ein kleiner Anblick aus dem Jenseits auf diesen späten Triumph wäre Reich zu gönnen. Dass die Menschheit davon noch nicht erlöst wurde, braucht er nicht zu wissen. Wir sind als Nachgeborene freier, was den Umgang mit Sexualität betrifft, und möchten nicht mehr auf diese Errungenschaft verzichten. Doch vielleicht haben sich die Probleme nur verlagert, denn wo die Marktlogik herrscht, wird alles käuflich. Ihre Ikonen ermüden wie die Bilder der Ausstellung, die nur in kleinen Dosen erregen und faszinieren. Dann, wenn auch ihre Geschichten erzählt werden, die Gespräche der Trinkgelage, das Liebesleid der Hetären und Tempelhuren, die Leidenschaften von Shiva und Parvati und die unendlich sich wiederholenden Niederlagen von liebenden Menschen und Göttern. Silikon und Sildenafil sind die Weihgaben an die Dämonen der Raserei, der Ekstase und der Zerstörung. Sie sind nur nützlich im Wissen, dass das eine ohne das andere nicht zu haben ist. Doch ohne das Lächeln der Aphrodite bleibt alles nur Elfenbein.

Liebeskunst - Liebeslust und Liebesleid in der Weltkunst. Museum Rietberg, Zürich; bis 27. April 2003. 